\title{
An Improved Fuzzy Entropy of Vague Sets Considering Hesitancy Degree
}

\author{
Weibing Feng ${ }^{1}$, Hairong Wang ${ }^{1, a}{ }^{*}$ \\ College of Science, Xi'an University of Science and Technology, China \\ *624863750@qq.com
}

Keywords: Vague sets; vague entropy; membership function; hesitancy degree

\begin{abstract}
The construction of fuzzy entropy is one of the research focuses in the field of vague sets. The existing fuzzy entropy formulae have three deficiencies: Firstly, as the increase of hesitancy degree, the change of entropy value is unstable; secondly, when the value of fuzzy entropy is 1 , the change of hesitancy degree has no effect on fuzzy entropy; thirdly, the existing entropy formulae do not fully satisfy the completeness of the definition of fuzzy entropy. Based on the comparative analysis, this paper introduces the hesitancy degree into the fuzzy entropy formulae, proposing a new entropy formula and proves its completeness theoretically. The new entropy formula takes into account both intuitiveness and fuzziness of the vague entropy and the comparative analysis of living examples shows that the improved entropy of Vague Sets overcomes the three drawbacks mentioned above, thus having better validity and rationality.
\end{abstract}

\section{Introduction}

Fuzzy-set theory, introduced by American scholar L.A. Zadeh in 1965 [1], is a basis for dealing with fuzzy problem. Fuzzy-set theory can only describe pro and con of information, but cannot solve voting problems very well. In order to avoid this defect, Vague sets theory was proposed by W.L. Gau and D.J. Buehrerin 1993 [2,3], which can not only express support and opposition information, but also express abstention information to depict the realization. It is no longer absolute and uncomplicated when coping with fuzzy uncertain information, after introducing the true and false membership function into vague sets. Zadeh first put forward to the concept of fuzzy entropy in 1969, measuring the fuzziness of fuzzy sets via entropy. The intuitionistic fuzzy sets that P. Burillo and H. Bustince established can only measure some ambiguous entropy, without involving in the truth-membership information and false-membership information [4]. E. Szmidt et al. deeply analyzed its definition and proposed fuzzy entropy based on fuzzy sets [5]. Subsequently, some scholars began to explore the characteristics and properties of the vague sets entropy, J.L. Fan constructed intuitive fuzzy entropy and analyzed the features which vague sets entropy should satisfy [6], P. Fan et al. proposed a new formula to explain the characteristics of the fuzzy entropy of vague sets using its unpredictability and uncertainty [7]. E. Szmidt explored the intuitionistic fuzzy sets of relationship among the truth-membership function, false-membership function and the hesitancy degree in term of the distance [8]. J.YE showed the intuitionistic fuzzy entropy of information measure with two methods and proposed the trigonometric function of fuzzy entropy [9]. F.S. Xu pointed out some deficiencies of the existing fuzzy entropy of vague sets in the terms of definition [10]. T.T. Zheng et al. determined the proportion of the fuzziness and uncertainty in fuzzy entropy of vague sets based on the idea of weight to depict the fuzzy degree of vague sets [11]. Intuitionistic fuzzy sets containing Atanassov operators is proposed by E. Szmidt [12],Q. Zhang introduced some new measures of the entropy for interval-valued intuitionistic fuzzy sets [13], X.J. Xie et al. explained the fuzzy entropy according to the characteristics of fuzziness and deficiency 
[14]. But the entropies mentioned above have certain deficiencies and fail to fully consider the absolute distance of truth-membership and false-membership; it cannot deeply probe the relation between the entropy of vague sets and hesitancy degree. Hence, this article gives the improved new vague sets axiomatic definition on the basis of the original entropy definition, and constructs new entropy of vague sets. The improved entropy has better validity and rationality through the analysis of experimental data and the theoretical evidence.

\section{The basic theory of Vague sets.}

Definition 1[2]: Let $U$ be the universe of discourse $U=\left\{u_{1}, u_{2} \cdots, u_{n}\right\}, \forall u_{i} \in U$.A vague set $A$ corresponds to two mappings.

$$
t_{A}\left(u_{i}\right) \rightarrow[0,1] ; f_{A}\left(u_{i}\right) \rightarrow[0,1]
$$

Where $0 \leq t_{A}\left(u_{i}\right)+f_{A}\left(u_{i}\right) \leq 1$, The numbers $t_{A}\left(u_{i}\right)$ and $f_{A}\left(u_{i}\right)$ denote the degree of membership and non-membership of $u_{i}$ to $A$, respectively.

Definition 2[2]: Let $\pi_{\mathrm{A}}\left(u_{i}\right)=1-t_{\mathrm{A}}\left(u_{i}\right)-f_{\mathrm{A}}\left(u_{i}\right)$, denote the degree of hesitancy of $u_{i}$ to $A$, It is obvious that $0 \leq \pi_{A}\left(u_{i}\right) \leq 1$.

Definition 3[3]: Let $\forall u_{i} \in U,\left[t_{\mathrm{A}}\left(u_{i}\right) 1-f_{A}\left(u_{i}\right)\right]$ be vague values of $u_{i}$ in vague set $A$.

Definition 4[2]: Let $A^{\mathrm{c}}$ be a vague set, then the complement of vague set is defined as follows:

$$
t_{\mathrm{A}^{\mathrm{c}}}\left(u_{i}\right)=f_{A}\left(u_{i}\right), 1-f_{\mathrm{A}^{\mathrm{c}}}\left(u_{i}\right)=t_{\mathrm{A}}\left(u_{i}\right)
$$

Definition 5[7]: Let $S_{\mathrm{A}}\left(u_{i}\right)$ be the nucleus of the vague set A, it expresses both trends of the absolute level of support and opposition.

$$
S_{\mathrm{A}}\left(u_{i}\right)=t_{\mathrm{A}}\left(u_{i}\right)-f_{\mathrm{A}}\left(u_{i}\right)
$$

\section{Existing definition of Vague sets entropy.}

At present, for the definition of vague sets entropy, most of them are based on the definitions as follows:

Definition 6: Let $E$ be a set-to-point mapping $E: F u z z y(U) \rightarrow[0,1], E$ is an entropy measure on $\operatorname{Fuzzy}(U)$ if the function $E(A)$ satisfies the following four properties, it is called fuzzy entropy.

(1) $E(A)=0 \Leftrightarrow$ For $\forall u_{i} \in U, A \in \operatorname{Fuzzy}(U)$;

(2) $E(A)=1 \Leftrightarrow$ For $\forall \mathrm{u}_{\mathrm{i}} \in U, t_{A}\left(u_{i}\right)=\left(u_{i}\right)=0$;

(3) $E(A)=E\left(A^{c}\right)$;

(4) $\forall u_{i} \in U$, if $A \ll B$, then $E(A)>E(B)$.

Due to the vague sets is a further generalization of Fuzzy sets, Form the definition of entropy formula that mentioned above we can obtain (Eq. (4)). Obviously, it is unreasonable to represent the hesitancy degree of intuitionistic fuzzy sets with intuitionistic fuzzy entropy. Therefore, we introduce the more perfect definition of literature [7].

Definition 7: Let $E$ be a set-to-point mapping $E: \operatorname{Vague}(U) \rightarrow[0,1], A$ be a vague fuzzy set in the universe of discourse $U$ if it satisfies the properties as follows, it is called vague entropy.

(1) $E(A)=0 \Leftrightarrow$ For $\forall u_{i} \in U, t_{A}\left(u_{i}\right)=0, f_{A}\left(u_{i}\right)=1$ or $t_{A}\left(u_{i}\right)=1, f_{A}\left(u_{i}\right)=0$;

(2) $E(A)=1 \Leftrightarrow$ For $\forall u_{i} \in U \Leftrightarrow t_{A}\left(u_{i}\right)=f_{A}\left(u_{i}\right)$;

(3) $E(A)=E\left(A^{c}\right)$;

(4)For $\forall u_{i} \in U$, if $t_{A}\left(u_{i}\right) \neq f_{A}\left(u_{i}\right), t_{B}\left(u_{i}\right) \neq f_{B}\left(u_{i}\right),\left|t_{A}\left(u_{i}\right)-f_{A}\left(u_{i}\right)\right|<\left|t_{B}\left(u_{i}\right)-f_{B}\left(u_{i}\right)\right|$ and $1-t_{A}\left(u_{i}\right)-f_{A}\left(u_{i}\right)=1-t_{B}\left(u_{i}\right)-f_{B}\left(u_{i}\right)$, then $E(A)>E(B)$;

(5) For $\forall u_{i} \in U$, if $t_{A}\left(u_{i}\right) \neq f_{A}\left(u_{i}\right), t_{B}\left(u_{i}\right) \neq f_{B}\left(u_{i}\right)$ and $1-t_{A}\left(u_{i}\right)-f_{A}\left(u_{i}\right)>1-t_{B}\left(u_{i}\right)-$ $f_{B}\left(u_{i}\right)$, then $E(A)>E(B)$.

Let $U$ be a universe of discourse, where $t_{A}\left(u_{i}\right) \in[0,1] ; f_{A}\left(u_{i}\right) \in[0,1]$ with the condition $0 \leq$ 
$t_{A}\left(u_{i}\right)+f_{A}\left(u_{i}\right) \leq 1$. Several forms of the vague entropy are presented as the following:

$$
\begin{aligned}
& \mathrm{E}_{\mathrm{BB}}(\mathrm{A})=\sum_{\mathrm{i}=1}^{\mathrm{n}}\left[1-\left(\mathrm{t}_{\mathrm{A}}\left(\mathrm{u}_{\mathrm{i}}\right)+\mathrm{f}_{\mathrm{A}}\left(\mathrm{u}_{\mathrm{i}}\right)\right)\right)=\sum_{\mathrm{i}=1}^{\mathrm{n}} \pi_{\mathrm{A}}\left(\mathrm{u}_{\mathrm{i}}\right), \\
& \mathrm{E}_{\mathrm{BB}}(\mathrm{A})=1-\frac{1}{2 \mathrm{n}} \sum_{\mathrm{i}=1}^{\mathrm{n}}\left|\mathrm{t}_{\mathrm{A}}\left(\mathrm{u}_{\mathrm{i}}\right)-\mathrm{f}_{\mathrm{A}}\left(\mathrm{u}_{\mathrm{i}}\right)\right| \text {, } \\
& E_{Y E}(A)=\frac{1}{n} \sum_{i=1}^{n} \frac{2 t_{A}\left(u_{i}\right) f_{A}\left(u_{i}\right)+\pi_{A}^{2}\left(u_{i}\right)}{t_{A}^{2}\left(u_{i}\right)+f_{A}^{2}\left(u_{i}\right)+\pi_{A}^{2}\left(u_{i}\right)} \\
& E_{X F}(A)=\frac{1-\left|t_{A}\left(u_{i}\right)-f_{A}\left(u_{i}\right)\right|+2 \pi_{A}\left(u_{i}\right)}{3},
\end{aligned}
$$

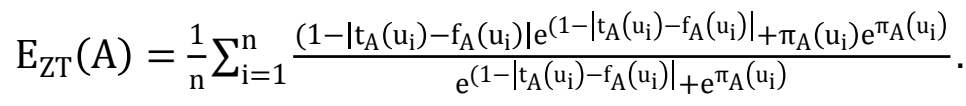

Above (Eq. (1)), which was completely determined by hesitancy degree; the (Eq. (2)) take into account the difference between membership degree and non-membership degree; For (Eq. (3),(4)), which was influenced by the distance of membership and the non-membership, as well as hesitancy degree, For (Eq. (1)-(4)), there exist three problems:

1) If $\left|t_{A}\left(u_{i}\right)-f_{A}\left(u_{i}\right)\right|=C \neq 0$ ( $C$ be a constant), then the change of entropy value is not stable with the increase of hesitancy degree,

2) If $\left|t_{A}\left(u_{i}\right)-f_{A}\left(u_{i}\right)\right|=0$, then $E(A)=1$ the value of entropy has no connection with the change of hesitancy degree,

3) The (Eq. (1)) does not satisfy the condition (4) and (5) of the definition 7, The (Eq. (2)-(4), (6)) does not satisfy the condition (5) of the defined 8.

\section{Improved entropy method based on Vague sets}

The entropy of vague sets is a generalization which existing fuzzy entropy. Vague sets contains the fuzziness and hesitancy degree, therefore, we must consider fuzziness and hesitancy degree in the definition of fuzzy entropy. For $\forall u_{i} \in U$, let $A$ is a vague set in a universe of discourse $U$, if $t_{A}\left(u_{i}\right) \rightarrow 1 / 0$ or $f_{A}\left(u_{i}\right) \rightarrow 0 / 1$, which presents the larger (smaller) degree of support and the smaller (larger) degree of opposition, and the fuzziness is little, if $t_{A}\left(u_{i}\right) \rightarrow 0$ and $f_{A}\left(u_{i}\right) \rightarrow 0$, then $\pi_{\mathrm{A}}\left(u_{i}\right) \rightarrow 1$, which presents the fuzziness is large and subordinate relationship is unstable. When the value of $E(A)$ is 0 that vague sets degenerate into fuzzy sets and fuzziness minimum, when the value of $E(A)$ is $1, t_{A}\left(u_{i}\right)=f_{A}\left(u_{i}\right)=0$, which presents the fuzziness is the largest. According to the second part (Eq. (2), (3)), based on the (Eq. (2)), which is determined by the difference of true-membership degree and false-membership degree, and the (Eq. (3)) consider the hesitancy degree, but when the entropy value is 1 , we couldn't obtain the change of hesitancy degree. Considering the (Eq. (2), (3)) are based on the difference of $t_{A}-f_{A}$ for structure entropy, which reflects the difference fuzziness of vague sets, we determine the coefficient through continuous improvement and a large number of experiments. Therefore, we propose the formula for the new axiomatic definition of entropy based on the original entropy of (Eq. (3), (5)) and literature [7].

Let $A=\left\{\left[u_{i}, t_{A}\left(u_{i}\right), f_{A}\left(u_{i}\right)\right] \mid u_{i} \in U\right\}$ be a vague set in the universe of discourse $U$, the improved entropy is constructed on the basis of (Eq. (3)).

$$
E_{N E W}(A)=\frac{1}{2 n} \sum_{i=1}^{n} \frac{1-\left|t_{A}\left(u_{i}\right)-f_{A}\left(u_{i}\right)\right|^{2}+3 \pi_{A}\left(u_{i}\right)}{2-\left|t_{A}\left(u_{i}\right)-f_{A}\left(u_{i}\right)\right|^{2}+2 \pi_{A}\left(u_{i}\right)} .
$$

Proof: (1) For $\forall u_{i} \in U, E_{N E W}(A)=0$, i.e. $1-\left|t_{A}\left(u_{i}\right)-f_{A}\left(u_{i}\right)\right|^{2}+3 \pi_{A}\left(u_{i}\right)=0$, Then $t_{A}\left(u_{i}\right)=$ 
$1, f_{A}\left(u_{i}\right)=0, \pi_{A}\left(u_{i}\right)=0$ or $t_{A}\left(u_{i}\right)=1, f_{A}\left(u_{i}\right)=0, \pi_{A}\left(u_{i}\right)=0$.

(2) For $\forall u_{i} \in U, E_{N E W}(A)=1$, i.e.

$$
1-\left|t_{A}\left(u_{i}\right)-f_{A}\left(u_{i}\right)\right|^{2}+3 \pi_{A}\left(u_{i}\right)=2-\left|t_{A}\left(u_{i}\right)-f_{A}\left(u_{i}\right)\right|^{2}+2 \pi_{A}\left(u_{i}\right),
$$

then $t_{A}\left(u_{i}\right)=f_{A}\left(u_{i}\right)$.

(3) For $\forall u_{i} \in U, E_{N E W}(A)=E_{N E W}\left(A^{c}\right)$, i.e.

$$
\frac{1}{2 n} \sum_{i=1}^{n} \frac{1-\left|t_{A}\left(u_{i}\right)-f_{A}\left(u_{i}\right)\right|^{2}+3 \pi_{A}\left(u_{i}\right)}{2-\left|t_{A}\left(u_{i}\right)-f_{A}\left(u_{i}\right)\right|^{2}+2 \pi_{A}\left(u_{i}\right)}=\frac{1}{2 n} \sum_{i=1}^{n} \frac{1-\left|f_{A}\left(u_{i}\right)-t_{A}\left(u_{i}\right)\right|^{2}+3 \pi_{A}\left(u_{i}\right)}{2-\left|f_{A}\left(u_{i}\right)-t_{A}\left(u_{i}\right)\right|^{2}+2 \pi_{A}\left(u_{i}\right)} .
$$

(4) For $\forall u_{i} \in U$, if $\left|t_{A}\left(u_{i}\right)-f_{A}\left(u_{i}\right)\right|<\left|t_{B}\left(u_{i}\right)-f_{B}\left(u_{i}\right)\right|$ and $\pi_{A}\left(u_{i}\right)=\pi_{B}\left(u_{i}\right)$,

We have $\quad \frac{1}{2 n} \sum_{i=1}^{n} \frac{1-\left|t_{A}\left(u_{i}\right)-f_{A}\left(u_{i}\right)\right|^{2}+3 \pi_{A}\left(u_{i}\right)}{2-\left|t_{A}\left(u_{i}\right)-f_{A}\left(u_{i}\right)\right|^{2}+2 \pi_{A}\left(u_{i}\right)}=\frac{1}{2 n} \sum_{i=1}^{n} 1-\frac{1-\pi_{A}\left(u_{i}\right)}{2-\left|t_{A}\left(u_{i}\right)-f_{A}\left(u_{i}\right)\right|^{2}+2 \pi_{A}\left(u_{i}\right)}$,

$$
\frac{1}{2 n} \sum_{i=1}^{n} \frac{1-\left|t_{B}\left(u_{i}\right)-f_{B}\left(u_{i}\right)\right|^{2}+3 \pi_{B}\left(u_{i}\right)}{2-\left|t_{B}\left(u_{i}\right)-f_{B}\left(u_{i}\right)\right|^{2}+2 \pi_{B}\left(u_{i}\right)}=\frac{1}{2 n} \sum_{i=1}^{n} 1-\frac{1-\pi_{B}\left(u_{i}\right)}{2-\left|t_{B}\left(u_{i}\right)-f_{B}\left(u_{i}\right)\right|^{2}+2 \pi_{B}\left(u_{i}\right)} .
$$

Then $\quad \frac{1}{2 n} \sum_{i=1}^{n} 1-\frac{1-\pi_{A}\left(u_{i}\right)}{2-\left|t_{A}\left(u_{i}\right)-f_{A}\left(u_{i}\right)\right|^{2}+2 \pi_{A}\left(u_{i}\right)}>\frac{1}{2 n} \sum_{i=1}^{n} 1-\frac{1-\pi_{B}\left(u_{i}\right)}{2-\left|t_{B}\left(u_{i}\right)-f_{B}\left(u_{i}\right)\right|^{2}+2 \pi_{B}\left(u_{i}\right)}$,

Therefore, $E_{N E W}(A)>E_{N E W}(B)$.

Theorem 1: Let $A=\left\{\left[u_{i}, t_{A}\left(u_{i}\right), f_{A}\left(u_{i}\right)\right] \mid u_{i} \in U\right\}$ be a vague sets in the universe of discourse $U$

$$
E_{N E W}(A)=\frac{1}{2 n} \sum_{i=1}^{n} \frac{1-\left|t_{A}\left(u_{i}\right)-f_{A}\left(u_{i}\right)\right|^{2}+3 \pi_{A}\left(u_{i}\right)}{2-\left|t_{A}\left(u_{i}\right)-f_{A}\left(u_{i}\right)\right|^{2}+2 \pi_{A}\left(u_{i}\right)},
$$

$\forall u_{i} \in U$, if $\left|t_{A}\left(u_{i}\right)-f_{A}\left(u_{i}\right)\right|^{2}<\left|t_{B}\left(u_{i}\right)-f_{B}\left(u_{i}\right)\right|^{2}, 1-t_{A}\left(u_{i}\right)-f_{A}\left(u_{i}\right)>1-t_{B}\left(u_{i}\right)-f_{B}\left(u_{i}\right)$, then, $E_{N E W}(A)>E_{N E W}(B)$.

Proof: For $\forall u_{i} \in U$, if $\left|t_{A}\left(u_{i}\right)-f_{A}\left(u_{i}\right)\right|=\left|t_{B}\left(u_{i}\right)-f_{B}\left(u_{i}\right)\right|$, we can obtain the result by the applying definition7, if $\pi_{A}\left(u_{i}\right)=\pi_{B}\left(u_{i}\right)$, we have $E_{N E W}(A)>E_{N E W}(B)$.

Let $u_{i}=\left[t_{A}\left(u_{i}\right) 1-f_{A}\left(u_{i}\right)\right], \pi_{A}\left(u_{i}\right)=1-t_{A}\left(u_{i}\right)-f_{A}\left(u_{i}\right)$, and $0 \leq t_{A}\left(u_{i}\right) \leq 1,0 \leq f_{A}\left(u_{i}\right) \leq 1$.

Therefore, we can get the inequality

$$
1-t_{A}\left(u_{i}\right)-f_{A}\left(u_{i}\right)<1-\left[t_{A}\left(u_{i}\right)-f_{A}\left(u_{i}\right)\right]<2-\left[t_{A}\left(u_{i}\right)-f_{A}\left(u_{i}\right)\right]
$$

When $0 \leq t_{A}\left(u_{i}\right)+f_{A}\left(u_{i}\right) \leq 1,0 \leq \pi_{A}\left(u_{i}\right) \leq 1$, we have $0<\pi_{A}\left(u_{i}\right)<2-\left[t_{A}\left(u_{i}\right)-f_{A}\left(u_{i}\right)\right]$, Due to the inequality $-1 \leq t_{A}\left(u_{i}\right)-f_{A}\left(u_{i}\right) \leq 1$ is hold,

Therefore

$$
\begin{gathered}
\left|t_{A}\left(u_{i}\right)-f_{A}\left(u_{i}\right)\right|^{2} \leq 1,2-\left|t_{A}\left(u_{i}\right)-f_{A}\left(u_{i}\right)\right|^{2} \geq 1, \\
E_{N E W}(A)=\frac{1}{2 n} \sum_{i=1}^{n} \frac{1-\left|t_{A}\left(u_{i}\right)-f_{A}\left(u_{i}\right)\right|^{2}+3 \pi_{A}\left(u_{i}\right)}{2-\left|t_{A}\left(u_{i}\right)-f_{A}\left(u_{i}\right)\right|^{2}+2 \pi_{A}\left(u_{i}\right)}=\frac{1}{2 n} \sum_{i=1}^{n} 1-\frac{1-\pi_{A}\left(u_{i}\right)}{2-\left|t_{A}\left(u_{i}\right)-f_{A}\left(u_{i}\right)\right|^{2}+2 \pi_{A}\left(u_{i}\right)} .
\end{gathered}
$$

Let $f\left(\pi_{A}\left(u_{i}\right)\right)=\frac{1-\pi_{A}\left(u_{i}\right)}{2-\left|t_{A}\left(u_{i}\right)-f_{A}\left(u_{i}\right)\right|^{2}+2 \pi_{A}\left(u_{i}\right)}<\frac{1}{2 \pi_{A}\left(u_{i}\right)}$, if $\pi_{A}\left(u_{i}\right)$ is increasing, then $f\left(\pi_{A}\left(u_{i}\right)\right)$ will reduce, then $E_{N E W}(A)$ is increasing, Thus, the improved vague entropy increases with the increase of hesitancy degree.

\section{Numerical examples}

The improved vague entropy is based on existing fuzzy entropy. Owing to fuzzy entropy only contains membership information, but vague entropy contains unknown information. Hence, we can compare with the difference of $t_{A}-f_{A}$ and hesitancy degree. For comparative analysis, we use the supplementary data in the literature [10].

It can be seen from Table 1, the membership degree of the vague sets $A$ is evaluated respectively $[0.4,0.7],[0.3,0.8]$ and $\left|t_{A}\left(u_{i}\right)-f_{A}\left(u_{i}\right)\right|=0.1 \neq 0$, when the hesitancy degree vary from 0.3 to 0.5 , we can find the increase-decrease characteristics of the $E_{S K}(A)$ and $E_{Y E}(A)$ is not changeable. when the value is $[0.4,0.8],[0.3,0.9]$, and $[0.2,1]$ of vague $A,\left|t_{A}\left(u_{i}\right)-f_{A}\left(u_{i}\right)\right|=$ 
$0.2 \neq 0$ and the hesitancy degree vary from 0.4 to 0.8 , we can find the increase-decrease characteristics of the $E_{S K}(A)$ is not changeable . Additional, the rest of the entropy increases with the increases of hesitancy degree. However, the increase-decreasecharacteristics of $E_{B B}(A)$ is not determined by the difference between true-membership and non-member, it only considers the influence on fuzziness and does not accord with people's cognition. For $E_{S K}(A)$, we only consider the difference of $t_{A}-f_{A}$ without taking into account the effect of hesitancy degree. Therefore, the $E_{B B}(A), E_{S K}(A)$ exist a problem that we mentioned above 1$)$.

Table 1.Comparison of vague entropy

\begin{tabular}{cccccccc}
\hline Number & 1 & 2 & 3 & 4 & 5 & 6 & 7 \\
\hline Values & {$[0,0]$} & {$[0.4,0.7]$} & {$[0.4,0.8]$} & {$[0.3,0.8]$} & {$[0.3,0.9]$} & {$[0.3,1]$} & {$[0.2,1]$} \\
\hline$\left|t_{A}-f_{A}\right|$ & 1 & 0.1 & 0.2 & 0.1 & 0.2 & 0.3 & 0.2 \\
$\pi_{A}$ & 0 & 0.3 & 0.4 & 0.5 & 0.6 & 0.7 & 0.8 \\
$E_{B B}(A)$ & 0 & 0.3 & 0.4 & 0.5 & 0.6 & 0.7 & 0.8 \\
$E_{S K}(A)$ & 0.5 & 0.95 & 0.9 & 0.95 & 0.9 & 0.85 & 0.9 \\
$E_{H L}(A)$ & 0 & 0.857 & 0.75 & 0.875 & 0.78 & 0.7 & 0.8 \\
$E_{Y E}(A)$ & 0 & 0.97 & 0.89 & 0.97 & 0.913 & 0.84 & 0.94 \\
$E_{X F}(A)$ & 0 & 0.5 & 0.53 & 0.63 & 0.67 & 0.7 & 0.8 \\
$E_{Z T}(A)$ & 0 & 0.69 & 0.64 & 0.74 & 0.71 & 0.7 & 0.8 \\
$E_{N E W}(A)$ & 0 & 0.365 & 0.391 & 0.42 & 0.44 & 0.45 & 0.48 \\
\hline
\end{tabular}

Table 2.Comparison of vague entropy

\begin{tabular}{ccccccccc}
\hline Number & 8 & 9 & 10 & 11 & 12 & $\begin{array}{c}\text { Entropy } \\
\text { Entropy }\end{array}$ \\
\cline { 1 - 5 } Values & {$[0.5,0.5]$} & {$[0.4,0.6]$} & {$[0.3,0.7]$} & {$[0.2,0.8]$} & {$[0,1]$} & 6 & 7 \\
\hline
\end{tabular}

\begin{tabular}{cccccccc}
\hline$t_{A}-f_{A} \mid$ & 0 & 0 & 0 & 0 & 0 & - & - \\
$\pi_{A}$ & 0 & 0.2 & 0.4 & 0.6 & 1 & - & - \\
$E_{B B}(A)$ & 0 & 0.2 & 0.4 & 0.6 & 1 & $\sqrt{ }$ & $\times$ \\
$E_{S K}(A)$ & 1 & 1 & 1 & 1 & 1 & $\sqrt{ }$ & $\times$ \\
$E_{\text {HL }}(A)$ & 1 & 1 & 1 & 1 & 1 & $\sqrt{ }$ & $\times$ \\
$E_{Y E}(A)$ & 1 & 1 & 1 & 1 & 1 & $\sqrt{ }$ & $\times$ \\
$E_{X F}(A)$ & 0.33 & 0.47 & 0.6 & 0.73 & 1 & $\sqrt{ }$ & $\sqrt{ }$ \\
$E_{\text {ZT }}(A)$ & 0.73 & 0.75 & 0.79 & 0.91 & 1 & $\sqrt{ }$ & $\times$ \\
$E_{\text {NEW }}(A)$ & 0.25 & 0.34 & 0.393 & 0.47 & 0.5 & $\sqrt{ }$ & $\times$ \\
\hline
\end{tabular}

It can be seen from Table 2 , if $\left|t_{A}\left(u_{i}\right)-f_{A}\left(u_{i}\right)\right|=0$, the entropy values of $E_{X F}(A), E_{N E W}(A)$, $E_{B B}(A)$, and $E_{X F}(A)$ are increased with hesitancy degree, but when entropy values of the $E_{N E W}(A)$ is 1 , there is no influence on the values of $E_{S K}(A), E_{H L}(A)$ and $E_{Y E}(A)$ with hesitancy degree, therefore, the $E_{S K}(A)$ exist a problem that mentioned above 2). The $E_{X F}(A), E_{Z T}(A)$ are the entropies that relevant literature mentioned in recent years. It is found that the improved entropy not only settles the problem that the above mentioned and has universal applicability, when the improved entropy belongs to two conditions, its values monotonically increasing.

For question three, Assume that $A=[0.3,0.3], B=[0.2,0.2]$ then $E_{B B}(A)=0$,it does not comply with the conditions (4) of the definition 7, The $E_{Z T}(A)$ also does not conform to the conditions (4) of the entropy definition 7, The $E_{S K}(A), E_{Y E}(A), E_{Z T}(A)$ and $E_{N E W}(A)$ are not in conformity with the conditions (5) of the entropy definition 7, thus, we construct the new entropy in view of the condition (5) of the entropy definition 7 is conforms to certain expectation, Therefore, the improved entropy of vague sets is reasonable and effective. 


\section{Conclusion}

In this paper, we analyze the exiting entropies' deficiency and further give the improved entropy formula of vague sets based on the difference of truth-membership and false-membership as well as hesitancy degree. It solves the problem that entropy value increases with hesitancy degree when the distance of truth-membership and false-membership is equal to a non-zero constant. The value of vague entropy is 1 , the change of hesitancy degree has no effect on vague entropy. The new entropy formula not only takes into account both intuitiveness and fuzziness of the vague entropy, but further verifies and corrects the definition of vague sets. Finally, the validity and rationality of vague entropy are verified by comparison and analysis, when the entropy value is 1 , the relationship between the change of the uncertainty and the entropy value need to be further studied and analyzed.

\section{References}

[1] L.A. Zadeh, Fuzzy sets, Information and Control, 8(1965), 338-353.

[2] W.L. Gau, D.J. Buehrer, Vague sets, IEEE Transactions on Systems Man \& Cybernetics, 23(2002), 610-614.

[3] J.K. Yu, S.J. Gao, and W. B. Zhang, Theoretical research and application of the theory of vague sets. Science Press, 2017, 45-49.

[4] P. Burillo, H. Bustince, Entropy on intuitionistic fuzzy sets and on interval-valued fuzzy sets, Fuzzy Sets and Systems 78(1996), 305-316.

[5] E. Szmidt, J. Kacprzyk, Some problems with entropy measures for the Atanassov intuitionistic fuzzy sets, Springer Berlin Heidelberg, 2007, 291-297.

[6] J.L. Fan, A few notes on fuzzy entropy in the vague sets, Fuzzy Systems and Mathematics, 20(2006), 105-110.

[7] P. Fan, J.R. Liang, and T.Z. Li, The new fuzzy entropy of the vague sets. Computer Engineering and Science, 43(2007), 179-181.

[8] E. Szmidt, J. Kacprzyk, A new similarity measure for intuitionistic fuzzy sets: straightforward approaches may not work, Fuzzy Systems Conference, 2007, 1-6.

[9] J. Ye. Two effective measures of intuitionistic fuzzy entropy. Computing, 87(2010), 55-62.

[10]F.S. Xu, New fuzzy entropy of the vague set, Computer Engineering and Science, 34(2012), 108-110.

[11]T.T. Zheng, Y.F .Chu, and B.P. Li, Study on the construction method of entropy, Computer Engineering and Application, 49(2013), 108-111.

[12]E .Szmidt, J. Kacprzyk, and P. Bujnowski, How to measure the amount of knowledge conveyed by Atanassov's intuitionistic fuzzy sets. Elsevier Science, 257(2014), 276-285.

[13]Q.S. Zhang, H.Y. Xing, F.C. Liu, et al, Some new entropy measures for interval-valued intuitionistic fuzzy sets based on distances and their relationships with similarity and inclusion measures, Information Sciences, 283(2014), 55-69.

[14]X.J. Xie, X.X. Lv, Improved interval-valued intuitionistic fuzzy entropy and its applications in multi-attribute decision making problems, Springer, 367(2016), 201-211.

[15]G.S. Huang, Y.S. Liu, The fuzzy entropy of vague sets based on non-fuzzy sets, Computer Applications \& Software, June, 2005. 